\title{
Addictive agents and intracranial stimulation: Daily amphetamine and hypothalamic self-stimulation
}

\author{
RICARDO DE OBALDIA, DEBRA J. MAGNUSON, and LARRY D. REID \\ Bradley University, Peoria, Illinois 61606
}

\begin{abstract}
Twenty adult male Sprague-Dawley rats were fixed with a chronically indwelling electrode for intracranial stimulation (ICS) of the lateral hypothalamus. Subsequently, rats pressed daily for four intensities of ICS, 2 min at each intensity. Subsequent to establishment of baseline pressing rates, rats were administered doses of amphetamine of $0, .5$, or $4 \mathrm{mg} / \mathrm{kg}$ for 26 days. Opportunities to press for ICS were given .5 and $23 \mathrm{~h}$ after injections. Following days of injections, there were further tests spanning 12 days. Initially, during the tests $.5 \mathrm{~h}$ after injections, the smaller dose of amphetamine slightly increased pressing over baseline and pressing of rats of $0 \mathrm{mg} / \mathrm{kg}$. Across days of injections the shift in pressing under the smaller dose was stable. Initially, the larger doses decreased pressing $.5 \mathrm{~h}$ after injections; however, across days of injections pressing increased to near baseline levels though never exceeding them. There were no discernible effects on pressing with tests $23 \mathrm{~h}$ after injections. Following the 26-day regimen of injections and testing, all press rates were at baseline levels.
\end{abstract}

Amphetamine at certain doses can accelerate pressing for lateral hypothalamic medial forebrain bundle (MFB) stimulation (Mogenson, 1968; Stein, 1964). Chronic use of amphetamine can produce something approaching psychoses in certain individuals (Bell, 1965; Connell, 1958; Ellinwood, 1967). Stein and Wise $(1969,1971)$ found amphetamine can increase available norepinephrine of the MFB system. They also suggested that affective psychoses are related to changes in levels of functional norepinephrine of the MFB system. These important relationships prompt the study of chronic doses of amphetamine and pressing for hypothalamic self-stimulation.

With rats pressing daily for hypothalamic intracranial stimulation (ICS), Miller, Bush, and Reid (1976) tested for the effects of 20 days of administration of 2- and $4-\mathrm{mg} / \mathrm{kg}$ doses of d-amphetamine with testing at 1,4 , and $23 \mathrm{~h}$ after injections. Under this regimen, doses hardly modified pressing rates. Following the termination of injections, however, pressing rates of rats getting amphetamines were slightly less than those of rats receiving a placebo. It was suggested by Miller et al. that tests using a range of intensities of ICS might demonstrate that amphetamine modified the site of ICS as potentially indexed by lowered pressing for some intensities of ICS subsequent to amphetamine. Consequently, this study tested for the effects of daily amphetamine on pressing for ICS across a range of intensities during and after daily doses of amphetamine. After testing with amphetamine, subjects received single doses of morphine and ethanol while pressing rates were tabulated.

\section{METHOD}

\section{Subjects}

Twenty adult male Sprague-Dawley rats were each fixed, using standard procedures, with a chronically indwelling bipolar platinum electrode (Plastic Products). The electrodes were insulated with Teflon except at the cross-section of the stimulating tips. Rats lived in individual cages with food and water always available. Subsequent to all behavioral testing, sites of ICS were verified by direct inspection of frozen sections of the subjects' brains and by inspection of photographs of enlarged images of those sections (Guzman-Flores, Alcarez, \& Fernandez, 1968). The primary structure of ICS was the MFB of the lateral hypothalamus.

\section{Apparatus}

The experimental chamber was a Plexiglas box $(30 \times 25 \times$ $43 \mathrm{~cm}$ ) equipped with a standard lever and flexible electrical leads attached to a slip ring assembly allowing free movement of rats. The chamber was housed within a larger sound-attenuating chamber. Each depression of the lever yielded ICS of $60-\mathrm{Hz}$ sine waves for $.25 \mathrm{sec}$ of varying intensities but always less than 50 microamperes, rms. Press rates were automatically recorded during any given $2-\min$ period.

\section{Procedure}

After 5 days for recovery from surgery, rats were tested to verify that they would press for ICS. During the first days of testing, intensity of ICS was varied and an intensity selected that sustained the highest press rates with minimal side effects such as seizures or forced movements. These selected intensities, which were used throughout procedures, varied from slightly above $\mathbf{2 0}$ microamperes to $\mathbf{4 0}$ microamperes. After selection of these intensities, rats were tested daily for $2 \mathrm{~min}$ each at 5,10 , 20 microamperes and the selected intensity. Each 2-min measurement for an intensity was preceded by at least 10 selfdelivered ICSs given while shaping to press. Testing was always 
begun with 5 microamperes and ended with the selected intensities. Rats continued with this daily regimen of testing every day until the behavioral procedures ended.

After rats' pressing became somewhat stable, a baseline measurement of pressing across six daily tests was taken. The scores of this baseline were taken as the standard to compare pressing subsequent to baseline. After baseline measurements, rats were divided into three groups. They were selected for groups such that average pressing was similar in the three groups. One group $(n=6)$ continued with daily sessions for ICS while getting placebo injections ( $1 \mathrm{ml} / \mathrm{kg}$ of physiological saline). Another group $(n=7)$ continued with sessions while getting $.5-\mathrm{mg} / \mathrm{kg}$ doses of d-amphetamine sulfate, while another $(\mathrm{n}=7)$ got $4.0-\mathrm{mg} / \mathrm{kg}$ doses. All injections were intraperitoneal.

Subjects were tested every day for 26 days, but for one half of the subjects the testing was $1 \mathrm{~h}$ before injections and for one half testing was $.5 \mathrm{~h}$ after injections. The half tested before injections on one day were then tested after injections on the next day. Consequently, there were 13 tests with each rat of effects after injections and 13 tests before injections, or there were tests .5 and $23 \mathrm{~h}$ after injections across 26 days of daily injections.

Subsequent to tests with daily amphetamine, testing continued for 12 days to assess the potential for postamphetamine effects. Subsequent to a 10-day rest period, rats were tested for 3 days to determine a new baseline for pressing. All rats then received an intraperitoneal ethanol injection $(.8 \mathrm{~g} / \mathrm{kg}$ using a $10 \% \mathrm{w} / \mathrm{v}$ solution) for one day with testing for effects on pressing for ICS $25 \mathrm{~min}$ after injection. Subsequent to this, there were another 3 days of base, after which all rats received morphine injections $(10 \mathrm{mg} / \mathrm{kg})$ subcutaneously and were tested $4 \mathrm{~h}$ later. After another 3 days of baseline testing, rats that had not previously received $.5-\mathrm{mg} / \mathrm{kg}$ amphetamine doses were tested at this dose $.5 \mathrm{~h}$ after injection. These tests were conducted to provide data for the determination of correlations between the effects on pressing under the influence of standard doses of amphetamine, ethanol, and morphine.

It was originally planned to administer doses of $6 \mathrm{mg} / \mathrm{kg}$ amphetamine, but this dose was found to almost completely suppress pressing for ICS when first administered. The dose for these rats was then adjusted to $4 \mathrm{mg} / \mathrm{kg}$ after some had received a dose of $6 \mathrm{mg} / \mathrm{kg}$. Consequently, the first data point in Figure 1 for the group of higher doses was excluded, as some rats had received $6 \mathrm{mg} / \mathrm{kg}$. The means for groups of $.5 \mathrm{mg} / \mathrm{kg}$ and $0 \mathrm{mg} / \mathrm{kg}$ are reported in Figure 1. The data of the first dosing for all groups, however, was not included in the statistical analyses.

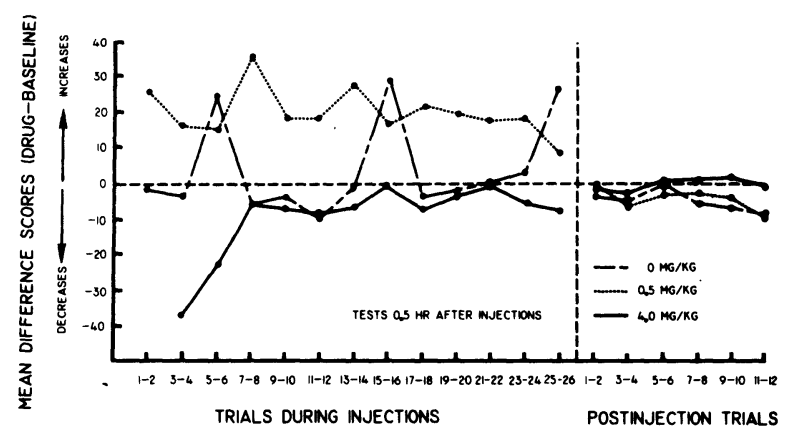

Figure 1. Results of testing with $0, .5$, and $4.0 \mathrm{mg} / \mathrm{kg}$ amphetamine averaged over intensities are shown for the 13 tests with ICS at $.5 \mathrm{~h}$ after injections. Also shown are the postinjection trials for the three groups. The numbers along the abscissa refer to days of testing, with one half of the testing on one day and the other half on the next day.

\section{RESULTS AND DISCUSSION}

A repeated measures analysis of variance (ANOVA) comparing the groups (as defined by their subsequent injections) across days of baseline indicated that groups did not differ prior to injections $[\mathrm{F}(2,17)=.19, \mathrm{p}>.50]$. Only the main effect associated with intensity was a reliable source of variance $[F(3,51)=68.3, p<.001]$, with rats pressing little for the 5 and 10 microamperes and pressing rapidly for the two higher intensities (mean presses $/ \mathrm{min}$ for 20 microamperes $=49.9$ ) . Consequently, there is no basis for concluding the groups' performance differed prior to injections.

The scores used in statistical analyses assessing drug and postinjection effects were difference scores. A difference score was obtained by subtracting the mean baseline score of a particular intensity from each of the comparable scores of tests under amphetamine and of tests following amphetamine injections. A negative score, therefore, indicates a decrease in pressing compared to baseline, while a positive score indicates an increase. Because difference scores were used, the effects of intensity seen with the ANOVA of baseline will not necessarily be manifest unless the drug produces differential effects with respect to intensity of ICS.

A 3 by 12 by 4 ANOVA having repeated measures, with factors of the three doses, the 12 days of testing, and the four intensities for data of $.5 \mathrm{~h}$ after injections, yielded an $F(2,17)=7.2, p<.006$ for the factor of group (dose of drug). No other main effect nor interaction was a reliable source of variance, although the triple interaction of Groups by Days of Testing by Intensity approached the standard for suggesting a reliable effect $[F(60,510)=1.3, p<.06]$. The higher dose of amphetamine tended to produce a greater relative decrease in pressing with lower intensities, particularly on the first days of injections. The control group's mean difference score across all intensities and days was 5.3 , whereas the $.5-\mathrm{mg} / \mathrm{kg}$ group's mean was 19.6 and the $4-\mathrm{mg} / \mathrm{kg}$ group's mean was -9.8 . The means and the results of the ANOVA indicate that the $.5-\mathrm{mg} / \mathrm{kg}$ dose led to slightly accelerated pressing, whereas the $4-\mathrm{mg} / \mathrm{kg}$ dose led to reduced pressing.

Figure 1 presents the data of $.5 \mathrm{~h}$ after injections for each of the groups averaged across intensities. As discernible from results of the ANOVA and from data of Figure 1, the scores of rats getting the $.5 \mathrm{-mg} / \mathrm{kg}$ doses did not change reliably across days of injections. The $4-\mathrm{mg} / \mathrm{kg}$ dose did produce more of a reduction in pressing on the first days of dosing than on subsequent days; however, this dose never led to mean increases in pressing. This relative lack of change in responsiveness under amphetamine is in marked contrast to the changes seen under daily doses of morphine.

Also presented in Figure 1 are scores of testing following injections. These scores are difference scores, 
again using preinjection baseline as the standard. As can be seen, the pressing of the groups of amphetamine is near baseline levels of pressing, that is, their difference scores were close to zero. An ANOVA of the data from which the means of postinjection scores of Figure 1 were derived provided no basis for concluding that groups differed (all ps $>.25$ ). Therefore, there is no support in these data for the hypothesis that prolonged dosing with amphetamine might reduce pressing for ICS subsequent to the dosing, a hypothesis suggested by Miller et al. (1976). An ANOVA of the data of $23 \mathrm{~h}$ after dosing also failed to discern any reliable differences in pressing either between groups or across days (all ps of the repeated measures ANOVA being $>.25$ ).

In general, the dose of ethanol suppressed pressing, $.5 \mathrm{mg} / \mathrm{kg}$ of amphetamine accelerated pressing, and the dose of morphine produced mixed effects. None of the correlations among difference scores indexing each drug's effect was of sufficient magnitude to be reliable. These results do not support a conclusion of Magnuson, Tadeusik, and Reid (1976) that there is a negative correlation between changes in pressing under amphetamine and morphine.

Since it has been shown by others (e.g., Carey, Goodall, \& Lorens, 1975) that smaller doses of amphetamine lead to accelerated pressing and that higher doses lead to reduced pressing, the only novel result of these tests is the relative lack of change observable across days of testing. Also, there are apparently limited effects of dosing that extend beyond injections. There were, however, some marked individual differences in rats' reactivity to amphetamine. Perhaps tests with more dosing or larger numbers of subjects might discern systematic shifts in pressing with chronic dosing. The limited available data, however, do not provide support for the idea that daily dosing with amphetamine produces a reliable shift in reactivity to reinforcing hypothalamic ICS that is not seen with single doses with the exception of some development of tolerance to the suppressive effects of large doses. We presume, therefore, that limited daily dosing with amphetamine does not produce enduring modifications of the medial forebrain bundle system.

\section{REFERENCES}

BELL, D. S. Comparison of amphetamine psychosis and schizophrenia. American Journal of Psychiatry, 1965, 111, 701-707.

Carey, R. J., Goodall, E., \& Lorens, S. Differential effects of amphetamine and food deprivation on self-stimulation of the lateral hypothalamus and medial frontal cortex. Journal of Comparative and Physiological Psychology, 1975, 88, 224-230.

Connell, P. H. Amphetamine psychosis. London: Chapman \& Hall, 1958.

Ellinwood, E. H., JR. Amphetamine psychosis. Journal of Nervous Mental Disease, 1967, 144, 273-283.

Guzman-Flores, C., Alcarez, M., \& Fernandez, A. Rapid procedure to localize electrodes in experimental neurophysiology. Boletin del Instituto de Estudios Medicos Y Biologicos, 1968, 16, 29-31.

Magnuson, D. J., Tadeusix, C. J., \& Reid, L. D. Addictive agents and intracranial stimulation: Self-stimulation under morphine, amphetamine, and chlorpromazine. Bulletin of the Psychonomic Society, 1976, 8, 459-462.

Miller, M. A., Bush, M. F., \& Reid, L. D. Addictive agents and intracranial stimulation: Daily amphetamine and hypothalamic self-stimulation. Bulletin of the Psychonomic Society, 1976, 8, 333-335.

Mogenson, G. J. Effects of amphetamine on self-stimulation and induced drinking. Physiology and Behavior, 1968, 3, 133-136.

STEIN, L. Self-stimulation of the brain and the central stimulant action of amphetamine. Federation Proceedings, 1964, 23, 836-850.

Stein, L., \& Wise, G. D. Release of norepinephrine from hypothalamus and amygdala by rewarding medial forebrain bundle stimulation and amphetamine. Journal of Comparative and Physiological Psychology, 1969, 67, 189-198.

Stein, L., \& Wise, G. D. Possible etiology of schizophrenia: Progressive damage to the noradrenergic reward system by 6-hydroxydopamine. Science, 1971, 171, 1032-1036.

(Received for publication December 30, 1976.) 